\title{
Development of Analysis Condition and Detection of Volatile Compounds from Cooked Hanwoo Beef by SPME-GC/MS Analysis
}

\author{
Hoa Van Ba, Maria Cynthia Oliveros, Kyeong-Seon Ryu, and Inho Hwang* \\ Department of Animal Science and Institute of Rare Earth for Biological Application, \\ Chonbuk National University, Jeonju 561-756, Korea
}

\begin{abstract}
The current study was designed to optimize solid phase microextraction (SPME)-GC-MS conditions for extraction and analysis of volatile components for Hanwoo beef and to establish a tentative database of flavor components. Samples were taken from Hanwoo longissimus muscle (30 mon old steer, $1^{+} \mathrm{B}$ carcass grade) at $24 \mathrm{~h}$ postmortem. Results indicated that the optimum adsorption time for $75 \mu \mathrm{m} \mathrm{CAR/PDMS} \mathrm{fiber} \mathrm{was} 60 \mathrm{~min}$ at $60^{\circ} \mathrm{C}$. Thermal cleaning at $250^{\circ} \mathrm{C}$ for $60 \mathrm{~min}$ was the best practice for decontamination of the fiber. A short analysis program with a sharp oven temperature ramp resulted in a better resolution and higher number of measurable volatile components. With these conditions, 96 volatile compounds were identified with little variation including 22 aldehydes, 8 ketones, 31 hydrocarbons, 12 alcohols, 8 nitrogen- and sulfurcontaining compounds, 5 pyrazines and 10 furans. A noticeable observation was the high number of hydrocarbons, aldehydes, ketones, alcohols and 2-alkylfurans which were generated from lipid decomposition especially the oxidation and degradation of unsaturated and saturate fatty acids. This implies that these compounds can be candidates for flavor specification of highly marbled beef such as Hanwoo flavor.
\end{abstract}

Key words: beef, flavor, volatile component, solid phase microextraction, gas chromatography-mass spectrometry

\section{Introduction}

Aroma compounds in cooked beef are generated from the oxidation and degradation of lipids, the interaction of lipid-degraded products through the Maillard reaction and thiamine degradation during heating (Mottram, 1998; Macleod, 1994). Studies have identified a number of compounds associated with particular flavor characteristics in cooked beef such as 2-acetyl-2-thiazoline and 2-ethyl3,5-dimethyl pyrazine (e.g., roasty, caramel-like burnt and earthy notes) (Cerny and Grosch, 1992), and 2-ethyl3,6-dimethylpyrazin, 2,3-diethyl-5-methylpyrazine and ethenylbenzene (e.g., burnt, pungent, roasty notes) (Specht and Baltes, 1994). Odor in stewed beef included 4 hydroxy-2,5-dimethyl-3(2H)-furanone, 12 methyl- tridecanal, methional, 3-hydroxy-4,5-dimethyl-2(5H)-furanone, and 2-furfurylthiol (Guth and Grosch, 1993).

Gas chromatography-mass spectrometry (GC-MS) has been widely used in identification of volatile components

*Corresponding author : Inho Hwang, Department of Animal Science, Chonbuk National University, Jeonju 561-756, Korea, Tel: 82-063-270-2605, Fax: 82-063-270-2605, E-mail: inho.hwang @jbnu.ac.kr in beef samples (Machiels et al., 2003; Moon et al., 2006; Raes et al., 2003; Stetzer et al., 2008). However, identified components varied depending on analysis conditions such as oven temperature, carrier gas flow rate and EM volts (Elmore et al., 2004; Machiels et al., 2003; McMaster, 2007; Gorraiz et al., 2002; Moon et al., 2006). Moon et al. (2006) identified 79 volatile compounds in simulated beef, but only 40 and 33 compounds were identified for roasted and boiled beef samples, respectively, under the same analysis condition. This suggested that heating condition interacts with analysis condition in terms of number and species of identified components in beef samples.

A number of techniques such as dynamic headspace, simultaneous steam distillation-solvent extraction (SDE), solid phase microextraction (SPME) have been developed to extract volatile compounds (Zhang and Pawliszyn, 1993). In recent years, SPME technique has been widely adopted to isolate aroma volatile compounds in cooked meat (Moon et al., 2006; Schilling et al., 2009; Stetzer et al., 2008; Yancey et al., 2006), because the other methods (i.e., dynamic headspace and SDE) require multi-step preparation, prolonged extraction time and high cost. On the other hand, previous studies showed that the extraction efficiency of volatile compounds in test samples by 
SPME fibers is significantly affected by several factors such as stirring condition, adsorption temperature, adsorption times, size of sample, the nature of the SPME fiber and salt addition (Kataoka et al., 2000; Lee et al., 2003; Moon and Li-Chan, 2004).

It is well documented that SPME fiber absorbs volatile components on the theory of equilibrium partitioning of the analytes between the solid phase of the fiber and volatile components of the specimen (Zhang and Pawliszyn, 1993). For these reasons, SPME fiber required various optimum conditions for different matrix; orange juice (55 $\left.\mathrm{min} / 25^{\circ} \mathrm{C}\right)(\mathrm{Jia}$ et al., 1998$)$, palm oil $\left(10 \mathrm{~min} / 50^{\circ} \mathrm{C}\right)(\mathrm{Bel}-$ tran et al., 2005; Ho et al., 2006), dry-cured hams (180 $\mathrm{min} / 40^{\circ} \mathrm{C}$ ) (Garcia-Gonzalez et al., 2008), simulated beef $\left(60 \mathrm{~min} / 60^{\circ} \mathrm{C}\right.$ ) (Moon and Li-Chan., 2004; Moon et al., 2006). The previous studies demonstrated the importance of extraction conditions for specific specimen. Although there are ample literatures available on analysis conditions of the above mentioned matrix, there are limited (if any) accessible reports on the analysis conditions for the highly marbled beef samples such as Hanwoo beef using SPME-GC/MS technique.

Cho et al. (2008) reported that Hanwoo beef have different fatty acid composition from imported beef, and that was a significant factor for Korean consumers' preference. Similarly, Hwang et al. (2004) reported that Hanwoo and imported beef can be discriminated by fatty acid composition. In a previous study, Hwang et al. (2004) concluded that Korean consumers preferred Hanwoo beef to imported one although toughness of Hanwoo was greater. It is well documented that flavor components of cooked meats are significantly influenced by pre-harvest (diets, sex, breed and stress) (Elmore and Mottram, 2000; Elmore et al., 2004; Enser et al., 1998) and post-harvest (chiller ageing, cooking methods and pH) (Jame and Kalkin, 2008; Stetzer et al., 2008; Young et al., 1993) factors. Given these, flavor components of Hanwoo beef can be another discriminator versus imported one, but we are unaware of any information on flavor components of highly marbled Hanwoo beef.

The current study was designed to optimize SPME-GC/ MS conditions for extraction and analysis of volatile components, and to establish a tentative database of flavor components for Hanwoo beef.

\section{Materials and Methods}

\section{Sample preparation and experimental design}

Muscle tissue samples were obtained from beef longis- simus muscle of Hanwoo steers ( 30 mon old, $1^{+} \mathrm{B}$ carcass grade) at $24 \mathrm{~h}$ postmortem. Subcutaneous fat and connective tissues were trimmed off. Samples were vacuumpacked and stored at $-20^{\circ} \mathrm{C}$ until use. Approximately $50 \mathrm{~g}$ of frozen samples were cut into small pieces, powdered in liquid nitrogen and stored at $-80^{\circ} \mathrm{C}$. Three separate experiments were designed to optimize 1) length of adsorption (30, 45, or $60 \mathrm{~min}$ ) into the SPME fiber (Carboxen/ PDMS, 75 ìm, Supelco Co.), 2) two GC-oven programs (36 or 50 min with different temperature ramps), and 3) conditions of thermal ageing (60 min-separate, $60 \mathrm{~min}$ simultaneous, or 80 min-simultaneous) for the SPME fiber as these conditions are one of the most critical aspects for extraction and separation of volatile components in meat samples (i.e., Alpendurada, 2000). All experiments were replicated three times.

\section{Experimental procedures \\ Experiment 1}

One gram powdered sample was placed in a $40 \mathrm{~mL}$ headspace vial sealed with PTFE-faced silicone septum (Supelco Co., USA) and cooked in an autoclave at $132^{\circ} \mathrm{C}$ for $30 \mathrm{~min}$. The cooked sample was immediately cooled in an ice bath to prevent further aroma development. An octagonal magnetic stirring bar was put into the vial and the vial was equilibrated at room temperature for $15 \mathrm{~min}$ if it was stored at $-20^{\circ} \mathrm{C}$ after cooking. Thereafter, it was placed into the $60^{\circ} \mathrm{C}$ water bath contained in a water jacket and allowed to equilibrate to $60^{\circ} \mathrm{C}$ for $10 \mathrm{~min}$. Water bath temperature was monitored by a Thermo recorder TR-52 (T \& D Corp., Japan). The SPME needle (Carboxen/PDMS, 75 ìm, Supelco Co., USA) was inserted into the PTFE/silicone septum and the fiber was exposed after the 10 min-equilibration period. The extraction process for volatiles was carried out at 30,45 or 60 $\min$. At the end of extraction, the fiber was retracted and immediately inserted into the GC-MS machine (Agilent Technologies 6890N, 5973 MSD, USA) for the analysis of volatile compounds. The fiber was exposed for $10 \mathrm{~min}$ in the $\mathrm{GC}$ injector $\left(250^{\circ} \mathrm{C}\right)$ and then retraction of the fiber into the needle (i.e., fiber holder). The needle was kept in the GC injector for an additional $50 \mathrm{~min}$. This was done separately from the sample analysis in the GC machine.

A DB-5MS capillary column, $30 \mathrm{~m} \times 0.25 \mathrm{~mm}$ i.d. $\times 0.25$ $\mu \mathrm{m}$ film thickness (Agilent J \& W Scientific, Model No. $122-5532$, Folcom, USA) was aged overnight at $230^{\circ} \mathrm{C}$. The SPME Carboxen/PDMS fiber was desorbed at $250^{\circ} \mathrm{C}$ at the injection port for $5 \mathrm{~min}$ with a split ratio of 10:1 and split flow of $10 \mathrm{~mL} / \mathrm{min}$. Helium was the carrier gas 
in constant pressure mode at $7.03 \mathrm{psi}$, flow rate of $1.0 \mathrm{ml} /$ min and average linear velocity of $36 \mathrm{~cm} / \mathrm{s}$. The $\mathrm{GC}$ oven was programmed to $40^{\circ} \mathrm{C}$ with $5 \mathrm{~min}$ holding time, increased to $250^{\circ} \mathrm{C}$ at a rate of $8^{\circ} \mathrm{C} / \mathrm{min}$, reaching $250^{\circ} \mathrm{C}$ at $31.25 \mathrm{~min}$. Holding time was $5 \mathrm{~min}$ thus total running time was $36.25 \mathrm{~min}$. MSD conditions were set as follows: capillary direct interface temperature, $250^{\circ} \mathrm{C}$; scanning mass range, 35-300 amu; electron multiplier voltage (Autotune $200 \mathrm{~V}$ ); scan rate, 5.27 scans/s (Schilling et al., 2009). These SPME-GC/MS conditions were used throughout all experiments except where other parameters were examined in experiments 2 and 3 .

\section{Experiment 2}

Sample preparation, extraction, adsorption, and analytical conditions were identical with those used in experiment 1 , but two temperature ramping conditions of the GC oven were compared. The first condition was programmed to $40^{\circ} \mathrm{C}$ with $5 \mathrm{~min}$ holding time, increased to $250^{\circ} \mathrm{C}$ at a rate of $8^{\circ} \mathrm{C} / \mathrm{min}$, reaching $250^{\circ} \mathrm{C}$ at $31.25 \mathrm{~min}$. Holding time was 5 min thus total running time was $36.25 \mathrm{~min}$. The other program included setting the GC oven at $40^{\circ} \mathrm{C}$ for $8 \mathrm{~min}$, increased to $200^{\circ} \mathrm{C}$ at a rate of $5^{\circ} \mathrm{C} / \mathrm{min}$. The $200^{\circ} \mathrm{C}$ temperature was reached at $40 \mathrm{~min}$ then was increased to $250^{\circ} \mathrm{C}$ at a rate of $10^{\circ} \mathrm{C} / \mathrm{min}$. Holding time was $5 \mathrm{~min}$, giving a total running time of $50 \mathrm{~min}$.

\section{Experiment 3}

Sample preparation, extraction, adsorption, and analytical conditions were identical with those used in experiment 1, but three conditioning (or ageing) of SPME fiber were evaluated. This trial was done for the fibers with three different adsorption times (30, 45 and $60 \mathrm{~min})$. The first method was the practical method described in experiment 1. The second method involved a 5 min exposure of the fiber in the GC injector, and then retraction into the needle which is left in the injection port until the completion of sample analysis (i.e., $36.25 \mathrm{~min}$ ). To complete the 60 min of thermal cleaning, the SPME needle was left in the injection port of the GC machine for an additional 29 min. Within the 29 min period, the SPME fiber was exposed for the first $10 \mathrm{~min}$, and retracted soon after, and the SPME needle was left in the machine for the last 19 min. The last method involved a 5 min exposure of the fiber in the GC injector, and then retracted into the needle which is left in the injection port until the completion of sample analysis (i.e., $36.25 \mathrm{~min}$ ). To complete the $80 \mathrm{~min}$ of thermal cleaning, the SPME needle was left in the injection port of the GC machine for an additional 49 min. Within the 49 min period, the SPME fiber was exposed for the first $10 \mathrm{~min}$, and retracted soon after, and the SPME needle was left in the machine for the last $39 \mathrm{~min}$.

\section{Data processing and identification}

The area of each peak was integrated using the ChemStation software (Agilent Technologies, Version D.01.00, USA). Integration parameters included initial threshold of 15 and peak width of 0.10 . The eluted compounds were initially identified by comparison of their mass spectra with those contained in the Wiley Registry of Mass Spectral Data $7^{\text {th }}$ edition (McLafferty, 2000; Agilent part no. G1035B) which contains 390,000 spectra and 316,934 compounds. The NIST Chemistry webBook $6^{\text {th }}$ edition (NIST Standard Reference Database number 69 containing 129,000 mass spectra, http://webbook.nist.gov/chemistry/ (2009) were simultaneously referred to for confirmation of compounds.

Secondly, peaks were further identified by Kovats indices calculated by applying a series of standard alkanes C8-C20 (Fluka, Cat. No. 04070, New Zealand). The retention indices of interest compounds were calculated based on the retention time of the alkanes according to the following equation: $\mathrm{RI}=100 \times \mathrm{n}(\mathrm{C})+100 \times[\mathrm{T}(\mathrm{a})-$ $\operatorname{Tn}(\mathrm{CS}) / \operatorname{Tn}(\mathrm{CL}) \mathrm{T}(\mathrm{a})]$ : where $\mathrm{n}(\mathrm{C})$ is the number of carbons; $\mathrm{T}(\mathrm{a})$ is the retention time of the compound of interest; $\operatorname{Tn}(\mathrm{CS})$ is the retention time of smaller hydrocarbons, and $\operatorname{Tn}(\mathrm{CL})$ is the retention time of larger hydrocarbon (Van den Dool and Kratz, 1963). The calculated retention indices were compared with available literature (Machiels and Istasse, 2003) who used exactly the same analytical column and cooking methods, and accessible database on the website (http://www.pherobase.com; El-Sayed, A.M. 2008. The Pherobase: database of insect pheromones and semiochemicals) which also used the same analytical conditions with the current study. One uL of the alkane standard solution (40 mg each alkane/L hexane) was injected under identical conditions.

Peaks were further confirmed by running various authentic compounds; pentanal, hexanal, heptanal, octanal, octenal, nonanal, E-2-hetenal, E-2-octenal, E,E-2,4-nonadienal, E,E-2,4-decadienal, E-2-nonenal, phenylacetaldehyde, 2-octanone, 1-octanol, pyrazine, 2-methylpyrazine and 1-pentanol (Aldrich, USA), 1-octen-3-ol, naphthalene, 2-heptanone and 2-hexanone (Fluka, Switzerland) and decanal (Sigma, USA). All these chemicals were diluted 100 times with acetone and $1 \mathrm{uL}$ of aliquot was injected to the GC/MS. 


\section{Results and Discussion}

\section{Conditioning method for volatile components of highly marbled beef}

Approximately 880 volatile compounds have been identified in cooked beef, and some of them are linked to the flavour characteristics (Rochat, 2005; 2007). As beef flavour has become the most important factor affecting preferences of consumers (Sitz et al., 2005), this area has been studied more widely than any other aspect of meats (Mottram, 1994). The aroma compounds generated during cooking are greatly influenced by the characteristics of fat (Macleod, 1994; Mottram, 1998) and Hanwoo beef showed unique fatty acid composition (Cho et al., 2008) in that oleic acid showed a higher proportion. This most likely greatly affects profile of volatile compounds of Hanwoo beef.

Table 1 shows the optimum length of adsorption time and it's relation to flavor compounds (Table 1). In this study, the adsorption temperature of $60^{\circ} \mathrm{C}$ was selected as previously reported (Moon et al., 2006), although others (Ho et al., 2006) recommended $50^{\circ} \mathrm{C}$ for all compounds and for an increment of non-heterocyclic compounds at $60^{\circ} \mathrm{C}$. The number of tentatively identified compounds adsorbed by the $75 \mu \mathrm{m}$ CAR/PDMS fiber at $60^{\circ} \mathrm{C}$ increased from 30, 45 to 60 with 67, 68 and 71 compounds, respectively. Nevertheless, the difference in the number of peaks was negligible, although the standard deviation greatly differ among the adsorption time; 1.52, 4.16 and 0.0 for 30,45 and $60 \mathrm{~min}$. The data indicate that the 60 min absorption time was the most consistent result between experiments and a higher chance of identification. For other matrix (i.e., orange flavor components), 20 $\min$ at $60^{\circ} \mathrm{C}$ was recommended for the same headspace sampling by the SPME fiber coated with $100 \mu \mathrm{m}$ polydimethylsiloxane (Zhang and Min, 1998). In addition, dry-cured hams showed different optimum absorption conditions; $180 \mathrm{~min}$ at $40^{\circ} \mathrm{C}$ by a Carboxen/PDMS/DVB fiber (Garcia-Gonzalez et al., 2008) and $180 \mathrm{~min}$ at $30^{\circ} \mathrm{C}$ by CAR/PDMS fiber (Flores et al., 2004). Absorption of volatile components into SPME fiber is a function of equilibrium partitioning of the analytes between the solid phase of the fiber and volatile components of the specimen (Zhang and Pawliszyn, 1993). Given this, except for length of time and temperature, other factors can affect the extend and rate of adsorption including size of samples, SPME fiber type and volume and stirring condition by accelerating the mass transfer between the sample and solid phase (Alpendurada, 2000; Wercinski and Pawliszyn, 1999). Our preliminary trial revealed that the number of peaks was decreased without stirring (data not shown).

Total peak area of volatile compounds was largest at 45 min. This change was not clearly understood, but it was reckoned that the longer adsorption time of up to $60 \mathrm{~min}$ may have gradually detached the concentrations some of

Table 1. Mean and standard variation for the number of volatile components, total peak area of the volatile compounds and number of tentatively identified compounds as a function of adsorption time $(30,45$ and $60 \mathrm{~min})$ at $60^{\circ} \mathrm{C} \mathrm{by} \mathrm{a} 75 \mu \mathrm{m}$ CAR/PDMS fiber in $40 \mathrm{~mL}$ headspace vial containing heated beef longissimus muscle at $132^{\circ} \mathrm{C}$ for 30 min $(\mathrm{n}=3)$

\begin{tabular}{lccc}
\hline \hline & \multicolumn{3}{c}{ Adsorption length (min) } \\
\cline { 2 - 4 } & 30 & 45 & 60 \\
\hline No. of peak & $66.7 \pm 1.52$ & $68.3 \pm 4.16$ & $71 \pm 0.0$ \\
Total area (Arbitrary units) & $1464141683 \pm 401053916$ & $2173514883 \pm 246271432$ & $1823149798 \pm 162065909$ \\
No. identified compounds ${ }^{1)}$ & 49 & 51 & 50 \\
\hline
\end{tabular}

${ }^{1}$ Tentatively identified based on ion spectra information in Wiley registry of Mass Spectral Data (2000).

Table 2. Mean and standard deviation for the number of volatile components, total peak area of the volatile compounds and number of tentatively identified compounds of cooked Hanwoo longissimus muscle at different elution conditions by varying oven temperature program $(n=3)^{1)}$

\begin{tabular}{lcc}
\hline \hline & Short analysis time with sharp temperature ramp ${ }^{3)}$ & Long analysis time with mild temperature ramp \\
\hline No. of peak & $71 \pm 00$ & $25.66 \pm 4.72$ \\
Total peak area & $1823149798 \pm 162065909$ & $285460420 \pm 47012500$ \\
No. identified compounds ${ }^{2)}$ & 50 & 24 \\
\hline${ }^{1)}$ Samples were cooked at $132^{\circ} \mathrm{C}$ for $30 \mathrm{~min}$ and volatile compounds were adsorbed at $60^{\circ} \mathrm{C}$ for 60 min by a $75 \mu \mathrm{m} \mathrm{CAR/PDMS} \mathrm{fiber} \mathrm{in}$ \\
$40 \mathrm{~mL}$ headspace vial. \\
${ }^{2)} \mathrm{Tentatively} \mathrm{identified} \mathrm{based} \mathrm{on} \mathrm{ion} \mathrm{spectra} \mathrm{information} \mathrm{in} \mathrm{Wiley} \mathrm{registry} \mathrm{of} \mathrm{Mass} \mathrm{Spectral} \mathrm{Data} \mathrm{(2000).}$ \\
${ }^{3)} 5 \mathrm{~min}$ at $40^{\circ} \mathrm{C}$, increased to $250^{\circ} \mathrm{C}$ at a rate of $8^{\circ} \mathrm{C} / \mathrm{min}$, holding for $5 \mathrm{~min}$. \\
${ }^{4)} 8 \mathrm{~min}$ at $40^{\circ} \mathrm{C}$, increased to $200^{\circ} \mathrm{C}$ at a rate of $5^{\circ} \mathrm{C} / \mathrm{min}$, increased to $250^{\circ} \mathrm{C}$ at a rate of $10^{\circ} \mathrm{C} / \mathrm{min}$, holding for $5 \mathrm{~min}$.
\end{tabular}


the volatile compounds that caused the decrease in total peak area. Similarly, in Kimchi (Lee et al., 2003) the compounds increased up to $30 \mathrm{~min}$ and thereafter decreased at longer than 30 min and Penton (1999) suggested that the adsorption time of SPME fiber should be no longer than the total GC run time for maximum productivity. On the other hand, Moon and Li-Chan (2004) reported that total peak area of volatile compounds in simulated beef was increased with longer adsorption time of up to $80 \mathrm{~min}$ at $60^{\circ} \mathrm{C}$. In the current study, adsorption for $45 \mathrm{~min}$ showed greater total peak area than $60 \mathrm{~min}$. However, we decided to using $60 \mathrm{~min}$ for following the succeeding experiment was considered because 45 min showed the largest standard deviation with less number of peaks. However, it should be emphasized that our results indicated that the optimum absorption adsorption time greatly depends on volatile components. For example, 2-hydroxy-2-ethenylbicyclo-octane and Tetradecentetradecen-1-ol acetate were only detected by at $30 \mathrm{~min}$ absorption, while Cyclopentanecyclopentane-1-2,4-trimethyl and Cyclopentanecyclopentane-1-3-dimethyl were detected by at 45 and 60 min. As shown in Table 4, there was a variation of detection between experiments. For 96 compounds identified in the current study many components were detected only once out of three trials. This implies that the analysis under these conditions should be done at least in triplicates.

Given that GC technique is a method of separating the

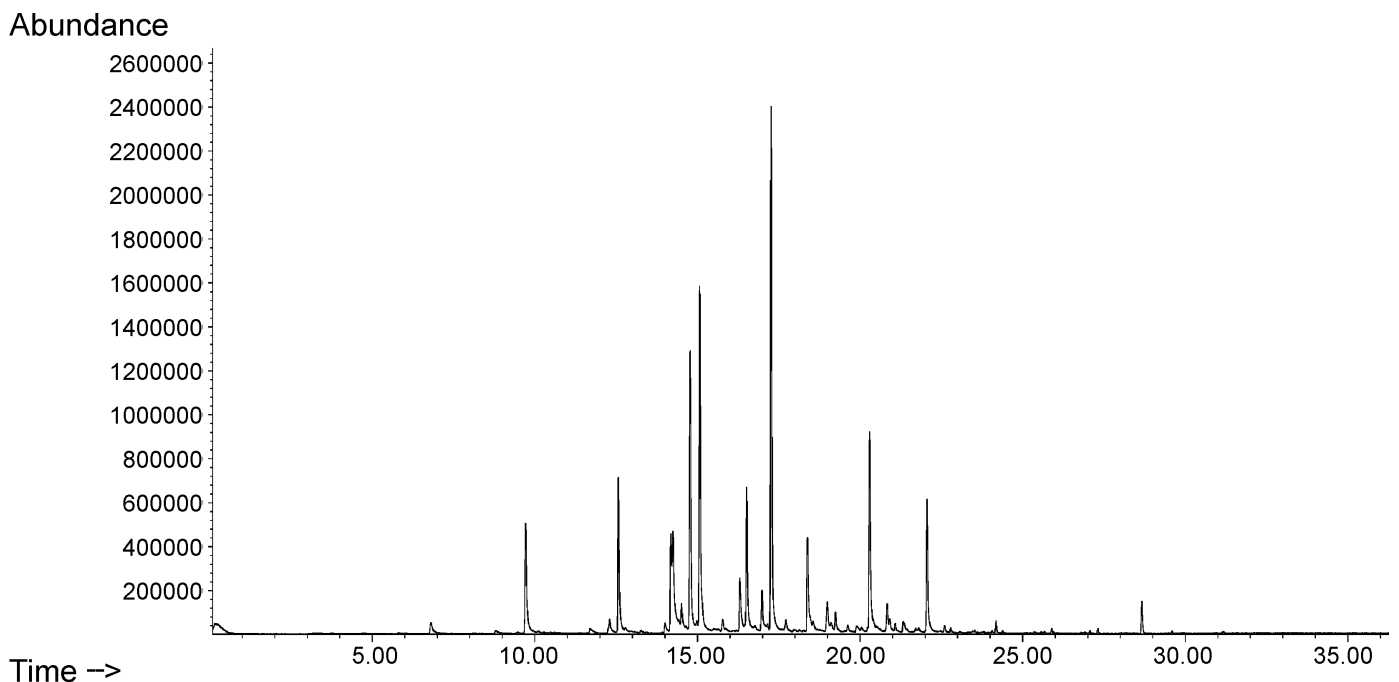

Abundance



Time $\rightarrow$

Fig. 1. Representative chromatograph of GC/MS spectra of Hanwoo longisimus muscle at different elution conditions by varying oven temperature profiles for experiment 2. Upper one was obtained from the program to $40^{\circ} \mathrm{C}$ with 5 min holding time, increased to $250^{\circ} \mathrm{C}$ at a rate of $8^{\circ} \mathrm{C} / \mathrm{min}$, reaching $250^{\circ} \mathrm{C}$ at $31.25 \mathrm{~min}$. Holding time was $5 \mathrm{~min}$ thus total running time was 36.25 min. Lower one was obtained from the program setting the $\mathrm{GC}$ oven at $40^{\circ} \mathrm{C}$ for $8 \mathrm{~min}$, increased to $200^{\circ} \mathrm{C}$ at a rate of $5^{\circ} \mathrm{C} / \mathrm{min}$. The $200^{\circ} \mathrm{C}$ temperature was reached at $40 \mathrm{~min}$ then was increased to $250^{\circ} \mathrm{C}$ at a rate of $10^{\circ} \mathrm{C} / \mathrm{min}$. Holding time was $5 \mathrm{~min}$, giving a total running time of $50 \mathrm{~min}$. 
different components of a mixture, oven temperature is a main focus in method development (Hajslova and Cajka 2008; McMaster, 2007). At the early stage of method development, a number of oven conditions were compared in terms of strength of separation, but ultimately two conditions (shorter time of $36 \mathrm{~min}$ with greater temperature ramp versus longer time of 50 min with slower temperature ramp) were considered. Assuming that most volatile components are evaporated at temperature lower than $100^{\circ} \mathrm{C}$, a gentle gradient of temperature ramp with longer analysis time was expectedly more a powerful program in terms of separation rate. However, the current results showed that a sharp temperature ramp has a greater number of peaks (71 peaks) than the other conditions (27 peaks). The former conditions showed zero standard variation compared with 4.72 for the other one. It was particularly noticeable that majority of components were eluted between $10 \mathrm{~min}$ to $22 \mathrm{~min}$ for the $36 \mathrm{~min}$ program, while those for the longer program were eluted between 13 to 32 min (Fig. 1). This reflects that volatile components start to elute between $65-80^{\circ} \mathrm{C}$ of oven temperature, but majority of the components are eluted at temperature higher than expected. Other factors such as types of columns, column ageing temperature and length of time, septum leaks, column pressure and split ratio greatly affect the resolution of volatile components (McMaster, 2007). An examination of a $60 \mathrm{~m}$ polar DB-WAX column, revealed a lower resolution than a $30 \mathrm{~m}$ non-polar DB-5MS (data not shown). Additionally, ageing of column at $230^{\circ} \mathrm{C}$ overnight was not effective compared to $300^{\circ} \mathrm{C}$ for $5 \mathrm{~h}$ in terms of stability and background noise. Column pressure at $5.0 \mathrm{psi}$ and split ratio at 30:1 were also not effective compared to the current conditions (data not shown).

The ultimate purpose of conditioning the SPME fiber is to eliminate contaminations and to stabilize according to the manufacturer's recommendation of $1 \mathrm{~h}$ at $300^{\circ} \mathrm{C}$. However, we observed a fact during preliminary studies that life time of the fiber was greatly affected by cleaning method and also the life time greatly influenced resolution and consistency of analysis. A number of cleaning methods were compared in terms of practical time and residual contaminants (Table 3). Initial observation showed that longer adsorption time $(60 \mathrm{~min})$ produced more residual components as compared to $30 \mathrm{~min}$ and $45 \mathrm{~min}$ adsorption time. The $60 \mathrm{~min}$ adsorption time resulted in one residual component (i.e., 2,6-Bis(1,1-dimethyl)-4-(1oxopropyl)phenol) for method 1 and two residual components (i.e., nonanal and benzeneacetaldehyde) for methods 2 and 3. On the other hand, the $30 \mathrm{~min}$ adsorption time showed two residual components (i.e., nonanal and benzeneacetaldehyde) only for method 2 . The identified residual compounds by methods 2 were also detected in our beef samples, and likely the most common contaminants during sampling or/and fundamentally could originated from cooked beef. However, the 2,6-Bis(1,1dimethyl)-4-(1-oxopropyl)phenol was not detected in the beef sample, and thus the source of contamination is unclear. An early study reported that the compound was frequently observed in the breath sample of piglet (Coggiola et al., 2004). Collectively, the first method, wherein the fiber were exposed for $10 \mathrm{~min}$ at $250^{\circ} \mathrm{C}$ (i.e., GC injector) and retracted into the fiber holder and kept for an additional $50 \mathrm{~min}$, appears to be the best practice. This conditioning process required additional analysis time between each sample as this conditioning process was

Table 3. Tentatively identified contaminants of SPME fiber ( $75 \mu \mathrm{m}$ CAR/PDMS) after completion of thermal conditioning when adsorption varied from 30,45 and $60(n=3)$

\begin{tabular}{cccc}
\hline \hline & \multicolumn{3}{c}{ Adsorption (min) } \\
\cline { 2 - 4 } & 30 & 45 & 60 \\
\hline Method 1 ${ }^{1)}$ & 0 & Nonanal naphthalene & 2,6-Bis(1,1-dimethyl)-4-(1-oxopropyl)phenol \\
Method 2 $^{2)}$ & Nonanal benzeneacetaldehyde & Nonanal & Nonanal benzeneacetaldehyde \\
Method 3 & 0 & 0 & Nonanal benzeneacetaldehyde \\
\hline
\end{tabular}

${ }^{1)}$ Fiber was exposed for $10 \mathrm{~min}$ in the GC injector, retracted into the fiber holder, and kept in the GC injector for an additional 50 min. This was done separate with sample analysis.

${ }^{2}$ Fiber was exposed for $5 \mathrm{~min}$ in the GC injector, retracted into fiber holder and left in the injection port until the completion of sample analysis (i.e., $36.25 \mathrm{~min}$ ). To complete the $60 \mathrm{~min}$ of thermal cleaning, the SPME needle was left in the injection port of the GC machine for an additional $29 \mathrm{~min}$. Within the $29 \mathrm{~min}$ period, the SPME fiber was exposed for the first $10 \mathrm{~min}$, and retracted soon after, and the SPME needle was left in the machine for the last $19 \mathrm{~min}$.

${ }^{3)}$ Fiber was exposed for $5 \mathrm{~min}$ in the GC injector, retracted into the fiber holder and left in the injection port until the completion of sample analysis. To complete the $80 \mathrm{~min}$ of thermal cleaning, the SPME needle was left in the injection port of the GC machine for an additional $49 \mathrm{~min}$. Within the $49 \mathrm{~min}$ period, the SPME fiber was exposed for the first $10 \mathrm{~min}$, and retracted soon after, and the SPME needle was left in the machine for the last $39 \mathrm{~min}$. 
done after the completion of each sample. Since few compounds remained after conditioning, the other methods also can be applied for thermal cleaning of fiber.

Electron multiplier (EM) voltage is one of the factors affecting the detection sensitivity. Abundance of the ions reported in the scan can be increased by elevating EM and that can be up to 3,500 V (McMaster, 2007). The effect of 200, 400 and $800 \mathrm{~V}$ on the number of peaks and total peak area of volatile compounds was examined (data not shown). Results showed that the number of peaks and total peak area increased with higher EM voltages. However, the use of up to $400 \mathrm{~V}$ for volatiles in beef samples was decided because a higher EM also generates basal noise. An EM voltage of 2,000 V and $1800 \mathrm{~V}$ for acidic non-steroidal anti-inflammatory drugs (Kim and Yoon, 1996) and for sweet basil (Yousif et al., 1999) were reported, respectively.

\section{Volatile compounds detected from Hanwoo longis- simus muscle}

It is well documented that Hanwoo genetically differs from other beef breeds (Lee et al., 2005) and its meat has unique fatty acid composition (Cho et al., 2008). However, there is no accessible database of the volatile compounds of Hanwoo beef. Table 4 presents the characteristics of the volatile compounds generated from Hanwoo longissimus muscle (30 mon old, $1^{+} \mathrm{B}$ carcass grade, $24 \mathrm{~h}$ postmortem) which was heated at $132^{\circ} \mathrm{C}$ for $30 \mathrm{~min}$. A total of 96 volatile compounds (22 aldehydes, 8 ketones, 31 hydrocarbons, 12 alcohols, 8 nitrogen- and sulfur-containing compounds, 5 pyrazines and 10 furans) were detected at three different adsorption times (30, 45 and 60 min). These compounds were initially identified by matching sample spectrum with the spectrum in the Wiley Registry of Mass Spectral Data $7^{\text {th }}$ edition (McLafferty, 2000). Some of them were again confirmed by comparing Kovats indices in available literatures and estimated values in the current study by applying standard alkanes. Furthermore, other components were confirmed by retention time estimated by running commercial available authentic components.

The current study initially indicates that majority of the compounds were similar with these previously reported in other breeds (e.g., Calkins and Hodgen, 2007; Machiels et al., 2003; Stetzer et al., 2008). However, there are a number of other chemicals that were identified from pork (e.g., tetradecanal) (Zhang and Pawliszyn,1993), bamboo (e.g., acetic acid) (Flores et al., 2004) and turkey and wine (e.g., 2-heptanol) (Brewer, 2009). Some others were identically reported from two or three different species (i.e, beef, chicken and pork) which include propanal, pentanal, hexanal, E,E-2,4-decadienal and 1-pentanol, dimethyl disulfide and methylbenzene (Table 4). Many compounds identified in the current study were not available from literatures although some of them were confirmed by authentic compounds and/or Kovat values. This may be an area for further study and can be candidates for breed specification of Hanwoo flavor.

The results of the present study showed a higher number of hydrocarbons, aldehyhydes, ketones, alcohols and 2-alkylfurans compared with the study of Gorraiz et al., (2002) using Pirenaica and Friesian bulls and heifers fed with commercial concentrate and ammonium-treated barley straw which were slaughtered at approximately 420$550 \mathrm{~kg}$ live weight with fat contents between 1.6 to $2.87 \%$. Considering the fact that these compounds are mostly generated from lipid decomposition especially the oxidation and degradation of unsaturated and saturated fatty acids (Macleod, 1994), the result is likely a consequence of the differences in fatty acid composition and fat content. Pyrazine compounds are generated from Maillard reaction and Strecker degradation and these contributes to the roasty flavor in cooked beef (Mottram, 1985). In the current study, only 5 pyrazine compounds were detected while Raes et al. (2003) reported 14 pyrazines from grilled European beef cattle. The difference can be attributed to different cooking methods, the inherit difference between breeds and/or pre- and post-slaughter interventions. There are a number of studies reporting that pyrazine compounds were detected for grilled or roasted beef samples, but not for boiled ones (Mussian and Walradt, 1974; Mottram, 1985; Moon et al., 2006).

The current study also revealed that analysis technique can affect the kind of detectable volatile compounds. It is not surprising since the principle of adsorption of volatile components on SPME fiber is based on the equilibrium partitioning of the analytes. This means that detectable volatile components in the specimen can vary depending on the time kinetic of equilibrium partitioning of the volatile components. Ketones were particularly affected by adsorption time ( 8 ketones for 30 and $45 \mathrm{~min}$ and 5 ketones for $60 \mathrm{~min}$ ). On the other hand, the other compounds were less affected by the length of adsorption time. A fundamental understanding for the changes is not known, but it was presumed that the 60 min adsorption at $60^{\circ} \mathrm{C}$ caused decomposition of the ketone compounds like 2-propanone, acetophenone, and 1-octen-3-one.

It can be concluded that the optimum adsorption time 
Table 4. List of identified volatile compounds from beef longissimus muscle adsorbed into the SPME fiber (Carboxen/PDMS, $75 \mu \mathrm{m})$ at different time of exposure at $60^{\circ} \mathrm{C}$ in a headspace vial $(n=3)$ and odor notes

\begin{tabular}{|c|c|c|c|c|c|c|c|c|c|c|c|c|}
\hline \multirow{2}{*}{ No } & \multirow{2}{*}{ Volatile compounds } & \multirow{2}{*}{$\mathrm{RT}^{2)}$} & \multirow{2}{*}{$\mathrm{LRI}^{3)}$} & \multicolumn{3}{|c|}{ Adsorption time (min) } & \multicolumn{4}{|c|}{ Identification } & \multirow{2}{*}{ Odor descriptors from literatures } & \multirow{2}{*}{ Medium } \\
\hline & & & & 30 & 45 & 60 & $\mathrm{ASC}^{4)}$ & $\mathrm{MS}^{5)}$ & RIL $^{6)}$ & $\mathrm{RID}^{7)}$ & & \\
\hline \multicolumn{13}{|c|}{ Aldehydes } \\
\hline 1 & Propanal & 6.776 & $>500$ & $+-+^{8)}$ & +++ & ++- & & $\mathrm{x}^{9)}$ & & & $\begin{array}{l}\text { Caramel, sweet, alcoholic, "cooked", broth, spicy, earthy, } \\
\text { mud (49) Caramel, cooked, brothy (4) }\end{array}$ & $\begin{array}{c}\text { Beef, } \\
\text { chicken, } \\
\text { pork }\end{array}$ \\
\hline 2 & Butanal & 6.87 & $>500$ & +-- & -++ & --- & & $\mathrm{x}$ & & & Smoky, fish, amylic, aldehyde-enal or dienal (49) & Beef \\
\hline 4 & Pentanal & 6.748 & $>500$ & +++ & +++ & +++ & $\mathrm{x}$ & $\mathrm{x}$ & & & $\begin{array}{l}\text { Almond, malt, pungent, acrid (5) Pungent, almond, malt } \\
\text { (4) }\end{array}$ & Beef, chicken \\
\hline 4 & Hexanal & 9.732 & 802 & +++ & +++ & +++ & $\mathrm{x}$ & $\mathrm{x}$ & $\mathrm{x}$ & $\mathrm{x}$ & $\begin{array}{l}\text { Fatty-green, grassy, strong green, tallow, fat, unripe fruit } \\
\text { when dilute (5) Grassy, rancid (4) (16) }\end{array}$ & $\begin{array}{l}\text { Beef, } \\
\text { chicken, } \\
\text { bamboo }\end{array}$ \\
\hline 5 & Heptanal & 12.569 & 903 & --- & +-- & --- & $\mathrm{x}$ & $\mathrm{x}$ & $\mathrm{x}$ & $\mathrm{x}$ & $\begin{array}{l}\text { Oily, fatty, rancid, unpleasant, penetrating fruity odor in } \\
\text { liquid (5) Green, fatty, oily, rancid (4) }\end{array}$ & Beef, chicken \\
\hline 6 & Benzaldehyde & 14.199 & 1129 & ++- & +++ & +++ & & $\mathrm{x}$ & $\mathrm{x}$ & & $\begin{array}{l}\text { Volatile almond oil, bitter almond, burning aromatic taste } \\
\text { (5) }\end{array}$ & Beef \\
\hline 7 & Octanal & 15.062 & 1004 & +-+ & --+ & ++- & $\mathrm{x}$ & $\mathrm{x}$ & $\mathrm{x}$ & $\mathrm{x}$ & $\begin{array}{l}\text { Harsh, fatty, orange peel, soapy, lemon, green, honey (5) } \\
\text { Sweet, fatty, soapy, fruit (4) }\end{array}$ & Beef, wine \\
\hline 8 & Octenal & 16.288 & 1210 & +-+ & +++ & +++ & $\mathrm{x}$ & $\mathrm{x}$ & $\mathrm{x}$ & $\mathrm{x}$ & Green, nut, fat (5) & Beef \\
\hline 9 & Nonanal & 17.25 & 1106 & +++ & +++ & +++ & $\mathrm{x}$ & $\mathrm{x}$ & $\mathrm{x}$ & $\mathrm{x}$ & Sea, aldehyde, citrus, green, citronella grass (49) & Beef \\
\hline & Decanal & 19.217 & 1131 & +-+ & -++ & +++ & $\mathrm{x}$ & $\mathrm{x}$ & $\mathrm{x}$ & $\mathrm{x}$ & $\begin{array}{l}\text { Fatty, rancid, meaty, burnt, tobacco, aldehyde, green over- } \\
\text { cooked (49) }\end{array}$ & Beef \\
\hline 11 & 3-Metylbutanal & 7.839 & $>500$ & ++- & -+- & +++ & & $\mathrm{x}$ & & & Bad, meaty, fish, rotten, aldehyde, valeric acid, fatty (49) & Beef \\
\hline 12 & 2-Metylbutanal & 9.238 & $>500$ & -+- & +++ & --- & & $\mathrm{x}$ & & & Nutty, burnt, onion (34) & Beef \\
\hline 13 & E-2-Heptenal & 14.022 & 1066 & -++ & +-+ & +++ & $\mathrm{x}$ & $\mathrm{x}$ & & & Fatty, tallowy (35) & Beef \\
\hline 14 & E-2-Octenal & 16.275 & 1158 & -++ & -++ & +++ & $\mathrm{x}$ & $\mathrm{x}$ & & & $\begin{array}{l}\text { Aldehyde, green, floral, dienal, fatty, cardboard, aldehyde, } \\
\text { amine (5) }\end{array}$ & Beef \\
\hline & E,E-2,4-Nonadienal & 16.952 & 2223 & -++ & -+- & -+- & $\mathrm{x}$ & $\mathrm{x}$ & $\mathrm{x}$ & $\mathrm{x}$ & $\begin{array}{l}\text { Dienal-enal, aldehyde, pan, swatted bug, fatty, bad, rancid } \\
\text { (49) Grassy, cucumber, rancid (3) }\end{array}$ & Beef, air \\
\hline 16 & E,E-2,4-Decadienal & 18.361 & 1211 & +-+ & --- & ++- & $\mathrm{x}$ & $\mathrm{x}$ & & $\mathrm{x}$ & Plastic, tailing odor (49) Fatty, fried potato, green (3) & Beef, chicken \\
\hline & $\begin{array}{l}\text { 3-Methyllthiophene-2-carboxylal- } \\
\text { dehyde }\end{array}$ & 18.986 & 1485 & +-+ & +-+ & -++ & & $\mathrm{x}$ & & & Mouldy, sulphurous (34) & Beef \\
\hline 18 & E-2-Nonenal & 16.416 & 1200 & --- & +++ & -+- & $\mathrm{x}$ & $\mathrm{x}$ & & & $\begin{array}{l}\text { Paper, fatty, iris, nauseating, aldehyde, dienal, wood, nutty, } \\
\text { nonylenic aldehyde (49) }\end{array}$ & Beef, wine \\
\hline 19 & E-2-Hexenal & 16.063 & 1106 & -+- & +++ & +++ & & $\mathrm{x}$ & & & Fruity, musty (34) & Beef \\
\hline 20 & Tetradecanal & 19.621 & 1242 & --+ & +++ & +++ & & $\mathrm{x}$ & & $\mathrm{x}$ & Roast, fried meat (58) & Pork \\
\hline
\end{tabular}




\begin{tabular}{|c|c|c|c|c|c|c|c|c|c|c|c|c|}
\hline \multirow{2}{*}{ No } & \multirow{2}{*}{ Volatile compounds } & \multirow{2}{*}{$\mathrm{RT}^{2)}$} & \multirow{2}{*}{$\mathrm{LRI}^{3)}$} & \multicolumn{3}{|c|}{ Adsorption time (min) } & \multicolumn{4}{|c|}{ Identification } & \multirow{2}{*}{ Odor descriptors from literatures } & \multirow{2}{*}{ Medium } \\
\hline & & & & 30 & 45 & 60 & $\mathrm{ASC}^{4)}$ & MS $^{5)}$ & RIL $^{6)}$ & $\mathrm{RID}^{7)}$ & & \\
\hline 21 & Phenylacetaldehyde & 21.3 & 1332 & $-++^{8)}$ & --- & +++ & $\mathrm{x}^{9)}$ & $\mathrm{x}$ & & $\mathrm{x}$ & Herb, oil, burning (42) & Simulated beef \\
\hline \multirow[t]{2}{*}{22} & Phenylacetaldehyde- $\alpha$ & 22.744 & 1410 & --- & --+ & -+- & & $\mathrm{x}$ & & & No reference & \\
\hline & Ketones & & & & & & & & & & & \\
\hline 1 & 3-Hydroxyl,2-butanone & 7.011 & $>500$ & --+ & ++- & +-- & & $\mathrm{x}$ & & & Buttery, rancid, beamy (3) & Beef, water \\
\hline 2 & 2-Hexanone & 9.515 & $>500$ & -++ & +++ & +-+ & $\mathrm{x}$ & $\mathrm{x}$ & & & No reference & \\
\hline 3 & 2-Propanone & 11.535 & 995 & --+ & ++- & --- & & $\mathrm{x}$ & & & Livery and bloody(16) & Beef \\
\hline 4 & 2-Heptanone & 12.222 & 870 & +++ & +++ & +++ & $\mathrm{x}$ & $\mathrm{x}$ & & & $\begin{array}{l}\text { Fruity, spicy, cinnamon, penetrating fruity odor in liquid } \\
\text { (5) }\end{array}$ & Beef \\
\hline 5 & 2-Octanone & 13.865 & 1028 & +++ & ++- & --- & $\mathrm{x}$ & $\mathrm{x}$ & & & Fruity, musty (35) & Beef \\
\hline 6 & Acetophenone & 16.958 & 2273 & +-+ & +++ & --- & & $\mathrm{x}$ & & & No reference & \\
\hline 7 & 2-Cyclohexanone-4-acetamido & 16.442 & 1281 & +++ & --+ & +-- & & $\mathrm{x}$ & & & No reference & \\
\hline \multirow[t]{2}{*}{8} & 1-Octen-3-one & 17.003 & 2820 & --- & +-- & --- & & $\mathrm{x}$ & & & Old water, mushroom, cellar (49) & Beef \\
\hline & Alcohols & & & & & & & & & & & \\
\hline 1 & Methyl-oxiran-yl-methanol ${ }^{1)}$ & 7.004 & $>500$ & -+- & --- & --- & & $\mathrm{x}$ & & & No reference & \\
\hline 2 & 1-Pentanol & 8.699 & $>500$ & --- & --+ & --- & $\mathrm{x}$ & $\mathrm{x}$ & & & Mild odor, fusel oil, fruit, balsamic (5) roasted meat (4) & Beef, pork \\
\hline 4 & 2-Octanol & 11.898 & 1178 & --- & -+- & --- & & $\mathrm{x}$ & & & No reference & \\
\hline 5 & 1-Octen-3-ol & 14.083 & 1085 & +++ & +-- & --- & $\mathrm{x}$ & $\mathrm{x}$ & & & $\begin{array}{l}\text { Mushrooms, compound excreted by many insects (4) } \\
\text { mushroom }(4,16)\end{array}$ & $\begin{array}{l}\text { Beef, air, } \\
\text { bamboo }\end{array}$ \\
\hline 6 & 2-Octen-1-ol & 14.07 & 1081 & ++- & +-- & --+ & & $\mathrm{x}$ & & & Green citrus (5) & Beef \\
\hline 7 & 2-Heptanol & 15.749 & 1059 & --- & +-+ & --+ & & $\mathrm{x}$ & & & Pork scrapings (4) Mushroom (16) & $\begin{array}{l}\text { Bamboo, } \\
\text { turkey, wine }\end{array}$ \\
\hline 8 & 1-Octanol & 16.487 & 1245 & --- & --+ & --+ & $\mathrm{x}$ & $\mathrm{x}$ & & & $\begin{array}{l}\text { Penetrating aromatic odor, fatty, waxy, citrus, oily, walnut, } \\
\text { moss, chemical, metal, burnt (4) }\end{array}$ & Beef \\
\hline 9 & 2-Nonen-1-ol & 17.539 & 1122 & -+- & --+ & ++- & & $\mathrm{x}$ & $\mathrm{x}$ & & No reference & \\
\hline 10 & 2-Butyl-1-octanol & 19.025 & 1555 & ++- & --- & --- & & $\mathrm{x}$ & & & No reference & \\
\hline 11 & Ethanol-2-bromo ${ }^{1)}$ & 21.043 & 1310 & --+ & +-+ & ++- & & $\mathrm{x}$ & & & No reference & \\
\hline \multirow[t]{2}{*}{12} & 2-Cyclohexene-1-ol ${ }^{1)}$ & 22.028 & 1510 & --- & --- & --+ & & $\mathrm{x}$ & & & No reference & \\
\hline & Hydrocarbons & & & & & & & & & & & \\
\hline 1 & Acetic acid & 7.897 & $>500$ & --- & ++- & --+ & & $\mathrm{x}$ & & & Vinegar (16) & Bamboo \\
\hline 2 & Toluene & 8.76 & $>500$ & +++ & +-+ & +++ & & $\mathrm{x}$ & & & No reference & \\
\hline 3 & 1H-Isoindole-1,3-(2H)-dithio ${ }^{1)}$ & 10.091 & 817 & $---^{8)}$ & --- & +-+ & & & $\mathrm{x}^{9)}$ & & No reference & \\
\hline 4 & 2-Methylene-cyclopentane ${ }^{1)}$ & 11.648 & 1035 & -+- & --- & --- & & & $\mathrm{x}$ & & No reference & \\
\hline 5 & 1,2-Ethtanediol ${ }^{1)}$ & 11.667 & 1043 & ++- & ++- & +++ & & & $\mathrm{x}$ & & No reference & \\
\hline
\end{tabular}




\begin{tabular}{|c|c|c|c|c|c|c|c|c|c|c|c|c|}
\hline \multirow{2}{*}{ No } & \multirow{2}{*}{ Volatile compounds } & \multirow{2}{*}{$\mathrm{RT}^{2)}$} & \multirow{2}{*}{$\mathrm{LRI}^{3)}$} & \multicolumn{3}{|c|}{ Adsorption time (min) } & \multicolumn{4}{|c|}{ Identification } & \multirow{2}{*}{ Odor descriptors from literatures } & \multirow{2}{*}{ Medium } \\
\hline & & & & 30 & 45 & 60 & $\mathrm{ASC}^{4)}$ & $\mathrm{MS}^{5)}$ & $\mathrm{RIL}^{6)}$ & $\mathrm{RID}^{7)}$ & & \\
\hline 6 & 3-octene & 11.782 & 1099 & $+++^{8)}$ & +++ & -+- & & & $\mathrm{x}^{9)}$ & & No reference & \\
\hline 7 & Styrene & 12.363 & 3002 & --- & --- & +-+ & & & $\mathrm{x}$ & & Penetrating odor, sweet smell (5) & Beef \\
\hline 8 & Hexane,3,3-dimethyl & 15.453 & 605 & --- & --- & +-- & & & $\mathrm{x}$ & & No reference & \\
\hline 9 & Heptane & 13.98 & 1055 & ++- & ++- & --- & & & $\mathrm{x}$ & & No reference & \\
\hline 10 & Cyclopentane-1-2,4-trimethyl ${ }^{1)}$ & 15.755 & 1059 & --- & +-+ & ++- & & & $\mathrm{x}$ & & No reference & \\
\hline 11 & Ethylmethylhexa-2,3-diene ${ }^{1)}$ & 15.781 & 1062 & +++ & +++ & +++ & & & $\mathrm{x}$ & & No reference & \\
\hline 12 & 2-Hexen -4yn-1-ol ${ }^{1)}$ & 16.092 & 1151 & +++ & +-- & --- & & & $\mathrm{x}$ & & No reference & \\
\hline 13 & Oxirine phenyl ${ }^{1)}$ & 16.195 & 1135 & +-- & --+ & --- & & & $\mathrm{x}$ & & No reference & \\
\hline 14 & 1-Pentyl-1-cyclohexene ${ }^{1)}$ & 17.7 & 1133 & --- & --+ & --+ & & & $\mathrm{x}$ & & No reference & \\
\hline 15 & Cyclotrisiloxane hexamethyl ${ }^{1)}$ & 18.373 & 1213 & +++ & +++ & --+ & & & $\mathrm{x}$ & & No reference & \\
\hline 16 & $\begin{array}{l}\text { Cycloxenane-1,1-(12,2-dimethyl- } \\
\text { butyl)1,3-propanedyil }{ }^{1)}\end{array}$ & 18.454 & 1230 & ++- & -++ & +-- & & & $\mathrm{x}$ & & No reference & \\
\hline 17 & Cyclopentane-1-3-dimethyl ${ }^{1)}$ & 18.996 & 1509 & --- & ++- & +++ & & & $\mathrm{x}$ & & No reference & \\
\hline 18 & Naphthalene & 19.057 & 1595 & --- & --- & --+ & & & $\mathrm{x}$ & $\mathrm{x}$ & No reference & \\
\hline 19 & Dodecane & 19.086 & 1178 & --- & --- & --+ & & & $\mathrm{x}$ & $\mathrm{x}$ & No reference & \\
\hline 20 & Nonane-3,7-dimethyl ${ }^{1)}$ & 19.099 & 1178 & --+ & +-- & --- & & & $\mathrm{x}$ & & No reference & \\
\hline 21 & Cyclooctene-1,2-dimethy ${ }^{1)}$ & 19.23 & 1184 & +-+ & ++- & +-- & & & $\mathrm{x}$ & & No reference & \\
\hline 22 & Pentedecene $^{1)}$ & 20.26 & 1324 & --- & --- & --+ & & & $\mathrm{x}$ & & No reference & \\
\hline 23 & $\begin{array}{l}\text { 2-Hydroxy-2-ethenyl-bicyclo- } \\
\text { octane }^{1)}\end{array}$ & 20.27 & 1327 & +++ & --- & --- & & & $\mathrm{x}$ & & No reference & \\
\hline 24 & Cyclotetrasiloxane octamethyl ${ }^{1)}$ & 20.617 & 1621 & -++ & +++ & --+ & & & $\mathrm{x}$ & & No reference & \\
\hline 25 & Propanoic acid & 20.764 & 2249 & +++ & +++ & --- & & & $\mathrm{x}$ & & Pungent, rancid, soy (3) & Air \\
\hline 26 & Tridecane & 20.886 & 1300 & --- & --- & -+- & & & $\mathrm{x}$ & $\mathrm{x}$ & Alkane (5) & Beef \\
\hline 27 & Tetradecen-1-ol acetate ${ }^{1)}$ & 21.056 & 1311 & +++ & --- & --- & & & $\mathrm{x}$ & & No reference & \\
\hline 28 & 11-Methyliden- Dodecen ${ }^{1)}$ & 21.99 & 1490 & -- & --+ & --- & & & $\mathrm{x}$ & & No reference & \\
\hline 29 & Phelethanolamine ${ }^{1)}$ & 22.032 & 1513 & +++ & +-+ & +++ & & & $\mathrm{x}$ & & No reference & \\
\hline 30 & Benzoic acid ${ }^{1)}$ & 23.508 & 1490 & +++ & $++-^{8)}$ & ++- & & $\mathrm{x}$ & & & No reference & \\
\hline \multirow[t]{2}{*}{31} & Silane trimethyl ${ }^{1)}$ & 28.026 & 1704 & ++- & --+ & -+- & & $\mathrm{x}$ & & & No reference & \\
\hline & $\begin{array}{l}\text { Nitrogen and sulfur containing } \\
\text { compounds }\end{array}$ & & & & & & & & & & & \\
\hline 1 & Pyrimidine-4-methyl ${ }^{1)}$ & 7.784 & $>500$ & --+ & ++- & --+ & & $\mathrm{x}$ & & & No reference & \\
\hline 2 & Dimethyl disulfide & 8.076 & $>500$ & +++ & +++ & +++ & & $\mathrm{x}$ & & & Moldy, rubbery, onion-like (34) Onion, cabbage, putrid (3) & Beef, chicken \\
\hline 3 & Methylbenzene & 8.737 & $>500$ & --- & --+ & -+- & & $\mathrm{x}$ & & & No reference & \\
\hline
\end{tabular}


for 75 um CAR/PDMS fiber was $60 \mathrm{~min}$ at $60^{\circ} \mathrm{C}$. Thermal cleaning at $250^{\circ} \mathrm{C}$ for $60 \mathrm{~min}$ was best for decontamination. A short analysis program with sharp oven temperature ramp resulted in a better resolution and higher number of volatile components. Non-polar column showed better resolution than polar column. A $400 \mathrm{EM}$ voltage appears to be the most practical condition for beef sample. These conditions enabled the identification of 96 volatile compounds with little variation, including 22 aldehydes, 8 ketones, 31 hydrocarbons, 12 alcohols, 8 nitrogen- and sulfur- containing compounds, 5 pyrazines and 10 furans.

\section{Acknowledgement}

We would like to acknowledge the financial support from RDA as a part of the FTA research program (\#200803A01081247).

\section{References}

1. Alpendurada, M. F. (2000) Solid-phase microextraction: a promising technique for sample preparation in environmental analysis. J. Chromatogr. 889, 3-14.

2. Beltral, G., Aguilera. M. P., and Gordon, M. H. (2005) Solid phase microextraction of volatile oxidation compounds in oil-water emulsions. J. Food Chem. 92, 401-406.

3. Bhuiyan, M. S. A., Yu, S. L., Jeon, J. T., Yoon, D., Cho, Y. M., Park, E. W., Kim, N. K., Kim, K. S., and Lee, J. H. (2009) DNA Polymorphisms in SREBF1 and FASN genes affect fatty acid composition in Korean cattle (Hanwoo). Asian-Aust. J. Anim. Sci. 22, 765-773.

4. Brewer, M. S. (2009) Irradiation effects on meat flavor: A review. Meat Sci. 81, 1-14.

5. Calkins, R. C. and Hodgen, J. M. (2007) A fresh look at meat flavour. Meat Sci. 77, 63-80.

6. Cerny, C. and Grosch, W. (1992). Evaluation of potent odorants in roasted beef by aroma extract dilution analysis. $Z$. Lebensm. For. 194, 322-325.

7. Cerny, C. and Grosch, W. (1994) Precursors of ethyldimethylpyrazine isomers and 2,3-diethyl-5-methylpyrazine formed in roasted beef. Z. Lebensm. For. 198, 210-214.

8. Cho, S. H., Kim, J. H., Kim, J. H., Park, B. Y., Hwang, I. H., Lee, J. M., Seong, P. N., and Kim D. H. (2008) Effect of fatty acid profiles on sensory properties of beef evaluated by korean and australian consumer groups. Food Sci. Biotechnol. 17, 495-500.

9. Choy, Y. H., Lee, C. W., Kim, H. C., Choi, S. B., Choi, J. G., and Hwang, J. M. (2008) Genetic models for carcass traits with different slaughter endpoints in selected Hanwoo herds I. Linear covariance models. Asian-Aust. J. Anim. Sci. 21, 1227-1232.

10. Coggiola, M. J., Oser. H., and Young. S. E. (2004) Volatile organic biomarkers in exhaled breath as a rapid, prodromal diagnosis of bioagent infection. Scientific Conference on Chem. Biol. Def. Res. Hunt Valley, MD.

11. El-Sayed, A. M. (2008) The Pherobase: Database of insect pheromones and semiochemicals. Available from: http:// www.pherobase.com, accessed on $18^{\text {th }}$ Oct. 2009.

12. Elmore, J. S. and Mottram, D. S. (2000) Formation of 2Alkyl-(2H)-thiapyrans and 2-Alkylthiophenes in cooked beef and lamb. J. Agri.. Food Chem. 2420-2424.

13.Elmore, J. S., Warren, H. E., Mottram, D. S., Scollan, N. D., Enser. M., Richardson, R. I., and Wood. J. D. (2004) A comparison of the aroma volatiles and fatty acid compositions of grilled beef muscle from Aberdeen Angus and Holstein-Friesian steers fed diets based on silage or concentrates. Meat Sci. 68, 27-33.

14. Enser, M. K., Hallett, G., Hewett, B., Fursey, G. A., Wood, J. D., and Harrington, G. (1998) Fatty acids content and composition of UK beef and lamb muscle in relation to production system and implications for human nutrition. Meat Sci. 49, 329-341.

15. Flores. M., Dura, M. A., Marco, A., and Toldra, F. (2004) Effects of Debaryomyces spp. on aroma formation and sensory quality of dry-fermented sausages. Meat Sci. 68, 439446.

16. Fu, S. G., Yoon, Y., and Bazemore, R. (2002) Aroma-active components in fermented bamboo shoots. J. Agric. Food Chem. 50, 549-554.

17. Garcia-Gonzalez, D. L., Tena, N., Ruiz, R. A., and Morales, M. T. (2008) Relationship between sensory attributes and volatile compounds qualifying dry-cured hams. Meat Sci. 80, 315-325.

18. Gorraiz, C., Beriain, M. J., Chasco, J., and Insausti, K. (2002) Effect of aging time on volatile compounds, odor, and flavor of cooked beef from Pirenaica and Friesian bulls and heifers. J. Food Sci. 67, 916-922.

19. Guth, H. and Grosch, W. (1993). 12-Methyltridecanal, a species-specific odorant of stewed beef. Lebensm. Wiss. Technol. 26, 171-177.

20.Hajslova, J. and Cajka, T. (2008) Gas chromatography in food analysis. In handbook of food analysis instrument. Semih, O. (ed), pp. 120-145.

21. Ho, C. W., Wan Aida, W. M., Maskat, M. Y., and Osman, H. (2006) Optimization of headspace solid phase microextraction (HS-SPME) for gas chromatography mass spectrometry analysis of aroma compounds in palm sugar (Arenga pinnata). J. Food Comp. Ana. 19, 822-830.

22. Hwang, I. H., Park, B. Y., Cho, S. H., Kim, J. H., and Lee, J. M. (2004) Meat quality of highly marbled imported beef with reference to Hanwoo. J. Anim. Sci Biotech.(Kor) 46, 659-666 (1598-9429).

23. James, J. M. and Calkins, C. R. (2008) The influence of cooking rate and holding time on beef chuck and round flavor. Meat Sci. 78, 429-437.

24. Jia, M, Zhang, H., and Min, D. (1998) Optimization of solid phase microextraction analysis for headspace flavour compounds of orange juice. J. Food Chem. 46, 2744-2747. 
25. Kataoka, H., Lord, H. L., and Pawliszyn, J. (2000) Applications of solid-phase microextraction in food analysis. $J$. Chromatogr. A 880, 35-62.

26. Kim, C. M., Kim, J. H., Oh, Y. K., Park, E. K., Ahn, G. C., Lee, G. Y., Lee, J. I., and Park, K. K. (2009) Effects of flaxseed diets on performance, carcass characteristics and fatty acid composition of Hanwoo steers. Asian-Aust. J. Anim. Sci. 22, 1151-1159.

27. Kim, K. R. and Yoon, H. R. (1996) Rapid screening for acidic non-steroidal anti-inflammatory drugs in urine by gas chromatography-mass spectrometry in the selected ion monitoring mode. J. Chromatogr. B 682, 55-66.

28. Koutsidis, G., Elmore, J. S., Oruna-Concha, M. J., Campo, M. M., Wood, J. D., and Mottram, D. S. (2007) Water-soluble precursors of beef flavour. Part II: Effect of post-mortem conditioning. Meat Sci. 79, 270-277.

29. Kwon, E. G., Park, B. K. Kim, H. C., Cho. Y. M., Kim T. I., Chang, S. S., Oh, Y. K., Kim, N. K., Kim, J. H., Kim, Y. J., Kim, E. J., Im, S. K., and Cho, N. J. (2009) Effects of fattening period on growth performance, carcass characteristics and lipogenic gene expression in Hanwoo steers. Asian-Aust. J. Anim. Sci. 22, 1654-1660.

30. Lee, J. H., Kang, J. H., and Min, D. B. (2003) Optimization of solid-phase microextraction for the analysis of the headspace volatile compounds in kimchi, a traditional Korean fermented vegetable product. J. Food Sci. 68, pp.844-848.

31. Lee, S. K., Panjono, Kang, S. M., Kim, T. S., and Park, Y. S. (2008) The effects of dietary sulfur and vitamin E supplementation on the quality of beef from the longissimus muscle of Hanwoo bulls. Asian-Aust. J. Anim. Sci. 21, 1059-1066.

32. Lee. J. H., Diono. R., Kim. G. Y., and Min. D. M. (2003) Optimization of solid phase microextraction analysis for the headspace volatile compounds of Parmesan cheese. J. Agric. Food Chem. 51, 1136-1140.

33. Li, S. and Weber, S. G. (1999) Selectivity in SPME In: Application of solid phase microextraction. Pauliszyn, J.(ed). The Royal Soc. Chem., Hertfordshine, pp. 49-57.

34. Machiels, D., Istasse, L., and Ruth, S. M. (2004) Gas chromatography-olfactometry analysis of beef meat originating from differently fed Belgian Blue, Limousin and Aberdeen Angus bulls. Food Chem. 86, 377-383.

35. Machiels, D. and Istasse. L. (2003) Gas chromatographyolfactometry analysis of the volatile compounds of two commercial Irish beef meats. Talanta 61, 529-537.

36. Machiels, D., van Ruth, S. M., Posthumus, M. A., and Istasse, L. (2003) Gas chromatography-olfactometry analysis of the volatile compounds of two commercial Irish beef meats. Talanta 60, 755-764.

37. Macleod, G. (1994) The flavour of beef, In: The flavour of meat and meat products. Shahidi. F (ed), Blackie, London, pp. 4-37.

38. Marco, A., Navarro, J. L., and Flores, M. (2006) The influence of nitrite and nitrate on microbial, chemical and sensory parameters of slow dry fermented sausage. Meat Sci. 73, 660-673.

39. McLafferty, F. W. (2000). Wiley registry of mass spectral data, 7th ed., Jonh Wiley \& Sons, NY.

40. McMaster, M. C. (2008) GC/MS: A practical user's guide. 2nd ed, John Wiley and Sons, Inc., Hoboken, NJ, p. 175.

41. Moon, S. Y. and Li-Chan, E. Y. C. (2004) Development of solid-phase microextraction methodology for analysis of headspace volatile compounds in simulated beef flavour. Food Chem. 88, 141-149.

42. Moon, S. Y., Cliff, M. A., and Li-Chan, E. C. Y. (2006) Odour-active components of simulated beef flavour analysed by solid phase microextraction and gas chromatographymass spectrometry and olfactometry. Food Res. Intl. 39, 294308.

43. Mottram, D. S. (1985) The effect of cooking conditions on the formation of volatile heterocyclic compounds in pork. $J$. Sci. Food and Agri. 36, 377-382.

44. Mottram, D. S. (1994) Meat flavour. In: Understanding natural flavors. Piggott, J. R. and Paterson, A. (eds.), Chapman and Hall, Glasgow, pp. 140-163.

45. Mussian, C. J. and Walradt, J. P. (1974) Volatile constituents of pressure cooked pork liver. J. Agri. Food Chem. 22, 827831.

46. NIST Standard Reference Database Number 69. (2009). NIST Chemistry WebBook, available from: http://webbook. nist.gov/chemistry/, accessed on $18^{\text {th }}$ Oct. 2009.

47. Penton, Z. (1999) Method development with solid phase microextraction. In: Solid phase microextraction- A practical guide. Wercinski, S. A. S. (ed), Marcel Dekker, Inc., NY, pp. 27-57.

48. Raes, K., Balcaen, A., Dirinck, P., Winne, A. D., Claeys, E., Demeyer, D., and Smet, S. D. (2003) Meat quality, fatty acid composition and flavour analysis in Belgian retail beef. Meat Sci. 65, 1237-1246.

49. Rochat, S. and Chaintreau, A. (2005). Carbonyl odorants contributing to the in-oven roast beef top note. J. Agric. Food Chem. 53, 9578-9585.

50. Rochat, S., de Saint Laumer, J. Y. and Chaintreau, A. (2007) Analysis of sulfur compounds from the in-oven roast beef aroma by comprehensive two dimensional gas chromatography. J. Chromatogr. A 1147, 85-94.

51. Schilling, M. W., Yoon, Y., Tokarskyy, O., Pham, A. J., Williams, R. C., and Marshall, D. L. (2009) Effects of ionizing irradiation and hydrostatic pressure on Escherichia coli O157:H7 inactivation, chemical composition, and sensory acceptability of ground beef patties. Meat Sci. 81, 705-710.

52. Shirey, R E. (1999). SPME fibers and selection for specific applications. In: Solid phase micro-extraction: a practical guide. Wercinski, S.A.S. (ed). Marcel Dekker, Inc., NY, pp. 59-110.

53. Sitz, B. M., Calkins, C. R., Feuz, D. M., Umberger, W. J., and Eskridge, K. M. (2005) Consumer sensory acceptance and value of domestic, Canadian, and Australian grass-fed beef steaks. J. Anim. Sci. 83, 2863-2868.

54. Specht, K. and Baltes, W. (1994) Identification of volatile flavor compounds with high aroma values from shallowfried beef. J. Agri. Food Chem. 42, 2246-2253.

55. Stetzer, A. J., Cadwallader, K., Singh, T. K., Mckeith, F. K., 
and Brewer, M. S. (2008) Effect of enhancement and ageing on flavor and volatile compounds in various beef muscles. Meat Sci. 79, 13-19.

56. Van den Dool, H. and Kratz, P. D. (1963) A generalization of the retention index system including linear temperature programmed gas-liquid partition chromatography. J. Chromatogr. 1, 463- 471.

57. Wercinski, S. A. S. and Pawliszyn, J. (1999) Solid phase microextraction theory. In Solid Phase Microextraction: A Practical Guide. Wercinski, S. A. S. (ed), Dekker, NY, pp. 126.

58. Xie, J., Sun, B., Zheng, F., and Wang, S. (2008) Volatile flavor constituents in roasted pork of mini-pig. Food Chem. 109, 506-514.

59. Yancey, E. J., Grobbel, J. P., Dikeman, M. E., Smith, J. S., Hachmeister, K. A., Chambers, I. V., Gadgil, P., Milliken, G. A., and Dressler, E. A. (2006) Effects of total iron, myoglo- bin, hemoglobin, and lipid oxidation of uncooked muscles on livery flavor development and volatiles of cooked beef steaks. Meat Sci. 73, 680-686.

60. Young, O. A., Reid, D. H., and Scales, G. H. (1993) Effect of breed and ultimate $\mathrm{pH}$ on the odor and flavor of sheepmeat. N. Z. J. Agri. Resource 36, 363-370.

61. Yousif, A. N., Scaman, C. H., Durance, T. D., and Girard, B. (1999) Flavor volatiles and physical properties of vacuummicrowaved- and air-dried sweet basil (Ocimum basilicum L.). J. Agric. Food Chem. 11, 4777-4781.

62. Zhang, M .J. Q. H. and Min, D. B. (1998). Pulsed electric field processing effects on flavor compounds and microorganisms of orange juice. Food Chem. 65, 445-451.

63. Zhang, Z. and Pawliszyn, J. (1993). Headspace solid-phase microextraction. Anal. Chem. 65, 1843-1852.

(Received 2009.10.26/Revised 2010.2.13/Accepted 2010.2.19) 